\title{
11-Keto-testosterone and Other Androgens of Adrenal Origin
}

\author{
Luboslav STÁRKA, Michaela DUŠKOVÁ, Jana VÍTKŮ \\ ${ }^{1}$ Institute of Endocrinology, Prague, Czech Republic
}

Received February 20, 2020

Accepted April 14, 2020

\begin{abstract}
Summary
The adrenal glands produce significant amounts of steroid hormones and their metabolites, with various levels of androgenic activities. Until recently, the androgenic potency of these adrenal-derived compounds were not well known, but some recent studies have shown that the production of 11-oxoand $11 \beta$-hydroxy-derived testosterone and dihydrotestosterone evidently have high androgenic activity. This fact has clinical importance, for instance, in various types of congenital adrenal hyperplasia with androgenization or polycystic ovarian syndrome, and laboratory determinations of these substances could help to better evaluate the total androgen pressure in patients with these disorders. Another area of concern is the treatment of prostate cancer with androgen deprivation, which loses effectiveness after a certain time. The concurrent blocking of the secretion of adrenal $\mathrm{C}_{19}$-steroids, whether using corticoids or adrenostatics, could increase the effectiveness of androgen-deprivation therapy.
\end{abstract}

\section{Key words}

$11 \beta$-hydroxy-testosterone • 11-keto-testosterone • Congenital adrenal hyperplasia $\bullet$ Prostate cancer $\bullet$ Adrenarche

\section{Corresponding author}

L. Stárka, Institute of Endocrinology, Národní 9, 11694 Prague 1, Czech Republic. E-mail: Istarka@endo.cz

\section{Introduction}

The androgen precursors dehydroepiandrosterone (DHEA) and DHEA sulfate (DHEAS) are produced in high amounts by the adrenal cortex, primarily in humans (3-25 mg/d) and in a few other primates. Another direct testosterone precursor, androstenedione (androst-4-ene3,17-dione), is produced in females in total daily amounts of $1.5-6 \mathrm{mg} / \mathrm{d}$, half of which occurs in the ovaries and half in the adrenals. The androgenic potential of these steroids is low. However, the human adrenal also secretes 11-oxygenated androgens (11-oxy-androgens), including $11 \beta$-hydroxy-androstenedione. Plasma levels of $11 \beta$-hydroxy-androstenedione (means $\pm \mathrm{SD}$ ) in healthy persons in the morning are $8.69 \pm 2.88$ (men), $7.72 \pm 2.85$ (women), $8.73 \pm 5.13$ (boys) and $7.88 \pm 5.23$ (girls) nmol/l, respectively. The concentrations of these hormones follow the circadian rhythm pattern of cortisol, increasing markedly after corticotropin stimulation and suppressed by dexamethasone (Putz et al. 1987). 11ß-hydroxyandrostenedione serves as the precursor of several highly potent androgens, the 11-oxygenated derivatives of testosterone and dihydrotestosterone.

\section{1-keto-testosterone and other androgens of adrenal origin}

Recently, the 11-oxygenated $\mathrm{C}_{19}$-steroids $11 \beta$-hydroxy-testosterone, 11-keto-testosterone, and $11 \beta$-hydroxy-dihydrotestosterone have arisen interest due to their high androgenic activity (Bloem et al. 2013, Turcu et al. 2018). 11-keto-testosterone has been known for decades to be the chief androgen produced in the male gonads of teleost fishes, identified in salmon plasma as early as 1960 (Idler et al. 1960). It is essential not only for fish spermatogenesis, but also for fish migration. Its occurrence in mammals was first described by Bun Ichi Tamaoki at the end of 60 's.

In contrast to fish, serum 11-keto-testosterone concentrations are similar in male and females of particular primate species, despite significantly higher circulating testosterone in males, suggesting that 11-ketotestosterone production in primate species is not gonaddependent and primarily originates from adrenal-derived 
11-oxy-androgen precursors (Rege et al. 2013, Rege et al. 2019, Imamichi et al. 2016).

The main production of 11ß-hydroxytestosterone is localized in the adrenals, and ACTH stimulates its concentration in the adrenal vein by several-fold (Rege et al. 2013). A small proportion of its daily secretion may occur in the ovaries, and an even smaller amount in the testes (Imamichi et al. 2016). The content of relative RNA for CYP11B1 is less than $2 \%$ in the ovaries and less than $1 \%$ in the testes in comparison with the adrenals. 11 -hydroxy-testosterone is formed principally from $11 \beta$-hydroxy-andostene-3,17-dione, by $17 \beta$-hydroxysteroid dehydrogenase. It can be converted to 11-keto-testosterone, which can be reduced extraadrenally by $5 \alpha$-steroid-reductase to the even more active 11-keto-dihydrotestosterone (Fig. 1). The relative androgenic activities of these bioactive androgens are listed in Table 1, where the values refer to the induction of the activation of androgen receptors relative to dihydrotestosterone (Storbeck et al. 2013). In addition, other measurements of the androgenic potency or efficacy (Rege et al. 2013, Pretorius et al. 2016) have confirmed the high androgenic potency of 11-keto-testosterone and 11-keto-dihydrotestosterone.

As far as we know, no study has yet assessed the relationships between 11-oxygenated $\mathrm{C}_{19}$-steroids and sex hormone-binding globulin (SHBG), and therefore to what extent the active free form contributes to its total activity.

The biosynthesis of 11-keto-testosterone and $11 \beta$-hydroxy-testosterone occurs as shown in Figure 1. $5 \alpha$-steroid reductases then produce 11-ketodihydrotestosterone and 11ß-hydroxydihydrotestosterone. The adrenal has low concentrations of the necessary $5 \alpha$-steroid reductases, and therefore the production of dihydrotestosterone derivatives takes place external to the adrenals. There may also be a back-door pathway in which 11\%-hydroxy-androstenedione is converted through $11 \beta$-hydroxy- $5 \alpha$-androstanedione to $11 \beta$-hydroxy-dihydrotestosterone (du Toit and Swart 2019). An analysis of the inactivation and reactivation of the metabolites also showed that dihydrotestosterone is more readily inactivated than 11-keto-dihydrotestosterone (du Toit and Swart 2020).

The high androgenic activity of the various metabolites (Table 1) as well as their relatively high concentrations in circulation was the reason why they have been the subject of much interest along with the classic androgens, especially testosterone. It has been observed that in control groups of healthy individuals the

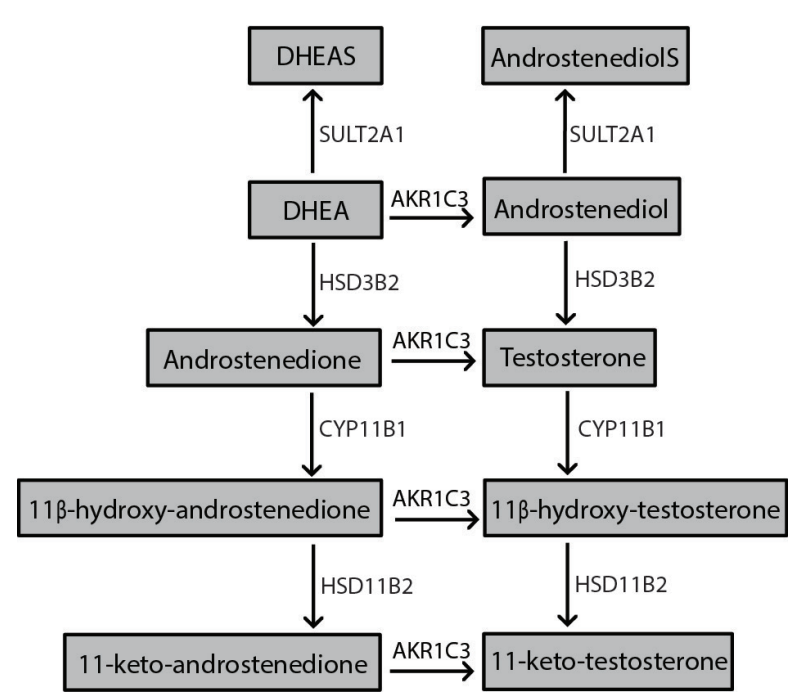

Fig. 1. Scheme of adrenal androgen formation. SULT2A1 sulfotransferase 2A1, AKR1C3 - 17ß-hydroxysteroid dehydrogenase type 5 , HSD3B2 - 33-hydroxysteroid dehydrogenase type 2, CYP11B1 - 11ß-hydroxylase, HSD11B2 $11 \beta$-hydroxysteroid dehydrogenase type 2 .

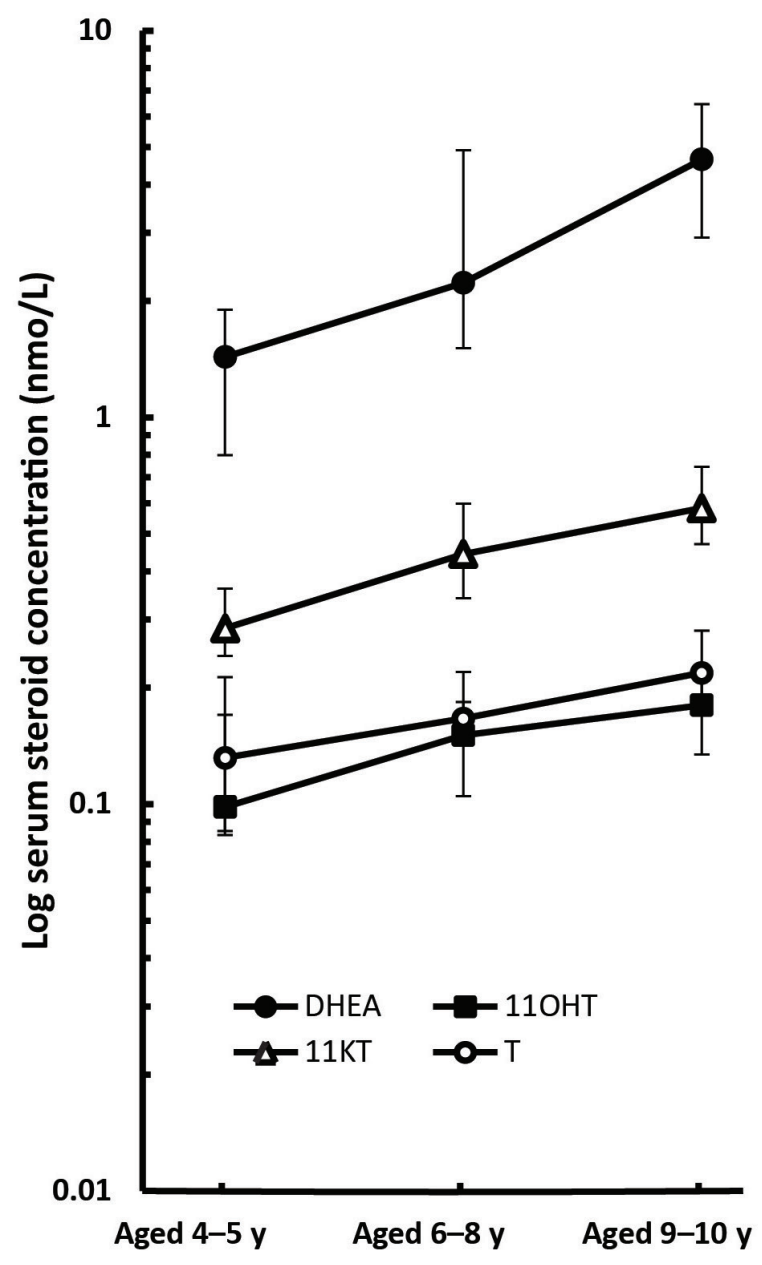

Fig. 2. Levels of $\mathrm{C}_{19}$-steroids in the course of adrenarche of girls aged 4-10 years (Rege et al. 2018). Data are expressed as median with corresponding interquartile range. DHEA dehydroepiandrosterone, 11KT - 11-keto-testosterone, 11OHT $11 \beta$-hydroxy-testosterone, $\mathrm{T}$ - testosterone. 
Table 1. Relative androgen potency of $\mathrm{C}_{19}$-steroids measured by androgen receptor activation (Storbeck et al. 2013).

Steroid

$\%$

$($ dihydrotestosterone $=100)$

\begin{tabular}{|c|c|}
\hline Androstenedione (androst-4-ene-3,17-dione) & $\mathrm{NM}(0.6 ; 2.0)$ \\
\hline Testosterone & 60.9 \\
\hline Dihydrotestosterone & 100 \\
\hline $11 \beta$-hydroxy-androstenedione & 2.3 \\
\hline 11-keto-androstenedione & 3.4 \\
\hline $11 \beta$-hydroxy-testosterone & 30.0 \\
\hline 11-keto-testosterone & 62.1 \\
\hline 11 $\beta$-hydroxy-dihydrotestosterone & 47 \\
\hline 11-keto-dihydrotestosterone & 96.2 \\
\hline
\end{tabular}

$\%$ - per cent induction of AR activation at 1 nmol concentration. NM - not measured in original study.

Table 2. Serum steroid concentrations (nmol/l) in patients with congenital adrenal hyperplasia due to the block of 21-hydroxylase (21OHD) and controls (Turcu et al. 2016).

\begin{tabular}{lcccc}
\hline Steroid & $\mathbf{2 1 O H D}(\mathbf{n}=\mathbf{3 8})$ & Controls $(\mathbf{n}=\mathbf{3 8})$ & Fold & $\boldsymbol{p}$-value \\
\hline $11 \mathrm{KAD}$ & $3.20[1.93-4.76]$ & $1.03[0.67-1.40]$ & 3.1 & $<0.0001$ \\
$11 \mathrm{OHT}$ & $1.94[0.69-3.41]$ & $0.49[0.30-0.67]$ & 4.0 & $<0.0001$ \\
$11 \mathrm{KT}$ & $5.66[3.48-12.12]$ & $1.66[0.96-2.58]$ & 3.4 & $<0.0001$ \\
DHEA & $1.01[0.56-2.95]$ & $6.07[4.09-11.04]$ & 0.2 & $<0.0001$ \\
$D H E A S$ & $507.96[212.65-1742.75]$ & $3788.15[1582.88-5059.49]$ & 0.1 & $<0.0001$ \\
\hline
\end{tabular}

Data are expressed as median [interquartile range]. Folds represent the $210 \mathrm{HD} /$ controls ratio and were calculated using the medians for each steroid. 11KAD - 11-keto-androstenedione, 11OHT - 11ß-hydroxy-testosterone, 11KT - 11-keto-testosterone.

levels of 11-keto-testosterone can be double the levels of testosterone. Concentrations of almost all 11-oxygenated $\mathrm{C}_{19}$-steroids have been found to be up to three times higher in patients with adrenal hyperplasia due to 21-hydroxylase deficiency compared to controls (Table 2) (Turcu et al. 2016, Storbeck et al. 2019). In addition, girls were shown to have more than doubled levels of 11-keto-testosterone compared to testosterone throughout the period of adrenarche (Fig. 2).

\section{Clinical importance}

When testosterone levels are followed for diagnostic or monitoring reasons, it seems reasonable to also measure levels of androgens of adrenal origin, especially 11-keto-testosterone and 11-ketodihydrotestosterone (Dušková et al. 2018). This is particularly true in cases of enzyme disorders with androgenization (Turcu et al. 2016, Turcu et al. 2017, Storbeck et al. 2019). In congenital adrenal hyperplasia due to 21-hydroxylase deficiency, levels of 11-ketotestosterone are on average three-times higher than in controls, while in contrast low levels are expected in 11ß-hydroxylase deficiencies, i.e. in $\mathrm{CAH}$ with hypertension. Following 11-keto-testosterone level can be useful in interpretation the significant androgenization of the skin and normal or only non-significantly increased testosterone level that occurs oft in the most common female endocrine disorder - polycystic ovarian syndrome (PCOS) (O’Reily et al. 2017, Yoshida et al. 2018). No evidence of the $11 \beta$-hydroxylation of androstenedione has been found in granulosa cells from the ovaries of women with PCOS (Owen et al. 1982), though another study indicated that 11-keto-testosterone is produced in the gonads (Imamichi et al. 2016). Higher adrenal activity in women with PCOS has been repeatedly observed (Turcu and Auchus 2017), but the concentrations of 11-oxygenated $\mathrm{C}_{19}$-steroids cannot be regarded as a marker for this syndrome. In some milder cases of female androgenization, for instance idiopathic 
hirsutism, the determination of 11-keto-testosterone and 11-keto-dihydrotestosterone could also help explain the conflict between the intensity of clinical features and the levels of testosterone or dihydrotestosterone.

In the recent publication (Skiba et al. 2019) has been demonstrated that 11-ketoandrostenedione and 11-ketotestosterone are stable across the menstrual cycle and make major quantitative contributions to the circulating androgen pool. All $\mathrm{C}_{19}$ androgens declined with age before menopause; hence, age-specific reference ranges are required for the interpretation of androgen levels in premenopausal women.

From a therapeutic standpoint, the adrenals are an important source of androgens that can fundamentally influence the current outlook regarding androgendeprivation therapies for prostate cancer (Storbeck et al. 2013, Swart et al. 2013, Pretorius et al. 2016, Barnard et al. 2018). Benign prostatic hyperplasia (BPH) tissue analysis has identified high levels of $11 \beta$-hydroxyandrosterone (4-14 ng/g) and 11ketoandrosterone $(9-160 \mathrm{ng} / \mathrm{g})$, together with androstenedione $(7.5 \mathrm{ng} / \mathrm{g})$ (du Toit and Swart 2020). The high activity of $5 \alpha$-steroid reductases in lymph node metastasis of prostate carcinoma (LNCaP) allows the production of the potent adrenal androgen 11-keto-dihydrotestosterone in the cells of prostate tumors (Barnard et al. 2018). Androgen deprivation therapy for prostate cancer relies on the principle of blocking the activity of gonadal androgens, either at the androgen receptor level or their production at the level of the hypothalamic-pituitarytesticular axis. After a certain time, usually around two years, initially successful therapies begin to become ineffective. It is likely that active adrenal androgens play a biologically-important active role during blockage of the biosynthesis of gonadal androgens. It is possible that together with blocking the gonadal production of androgens, a concurrent blocking of adrenal function, either through corticoids, adrenostatics, or even adrenalectomy, could allow androgen deprivation therapy to continue to be effective.

\section{Conclusions}

The finding that some 11-oxygenated $\mathrm{C}_{19}$-steroids have androgenic activity as high as the classical androgens testosterone and dihydrotestosterone, with levels in circulation similar to these steroids, has led to a change in perspective in current laboratory diagnostics for markers of androgenization. In the future, it would be advantageous to measure not just testosterone, free testosterone and dihydrotestosterone, but also levels of 11-keto-testosterone and 11-ketodihydrotestosterone in particular. These data should make the hormonal picture of hyperandrogenic disorders such as some types of congenital adrenal hyperplasia or polycystic ovarian syndrome more complete. Blocking the adrenal production of 11-oxygenated $\mathrm{C}_{19}$-steroids together with blocking testicular hormone production could also lead to improvements in therapies for conditions where the presence of androgens are a negative factor, such as prostate cancers.

\section{Conflict of Interest}

There is no conflict of interest.

\section{Acknowledgements}

Supported by Ministry of Health CR, RVO (Institute of Endocrinology - EU, 00023761).

\section{References}

AZZIZ R, BLACK V, HINES GA, FOX LM, BOOTS LR: Adrenal androgen excess in the polycystic ovary syndrome: sensitivity and responsivity of the hypothalamic-pituitary-adrenal axis. J Clin Endocrinol Metab 83: 2317-2323, 1998. https://doi.org/10.1210/jc.83.7.2317

BARNARD M, QUANSON JL, MOSTAGHEL E, PRETORIUS E, SNOEP, STORBECK KH: 11-Oxygenated androgen precursors are the preferred substrates for aldo-keto reductase 1C3 (AKR1C3): implications for castration resistant prostate cancer. J Steroid Biochem Mol Biol 183: 192-201, 2018. https://doi.org/10.1016/j.jsbmb.2018.06.013

BLOEM LM, STORBECK KH, SCHLOMS L, AMANDA C, SWART AC: $11 \beta$-Hydroxyandrostenedione returns to the steroid arena: biosynthesis, metabolism and function. Molecules 18: 13228-13244, 2013. https://doi.org/10.3390/molecules181113228

DUŠKOVÁ M, KOLÁTOROVÁ L, STÁRKA L: Androgens in women - critical evaluation of the methods for their determination in diagnostics of endocrine disorders. Physiol Res 67 (Suppl 3): S379-S390, 2018. https://doi.org/10.33549/physiolres.933964 
DU TOIT T, SWART AC: Inefficient UGT-conjugation of adrenal 11 $\beta$-hydroxyandrostenedione metabolites highlights C11-oxy C19 steroids as the predominant androgens in prostate cancer. Mol Cell Endocrinol 461: 265-276, 2018. https://doi.org/10.1016/j.mce.2017.09.026

DU TOIT T, SWART AC: The 11 -hydroxyandrostenedione pathway and C11-oxy C21 backdoor pathway are active in benign prostatic hyperplasia yielding 11keto-testosterone and 11keto-progesterone. J Steroid Biochem Mol Biol 196: 105497, 2020. https://doi.org/10.1016/j.jsbmb.2019.105497

IMAMICHI Y, YUHKI KI, ORISAKA M, KITANO T, MUKAI K, USHIKUBI F, TANIGUCHI T, UMEZAWA A, MIYAMOTO K, YAZAWA T: 11-keto-testosterone is a major androgen produced in human gonads. Clin Endocrinol Metab 101: 3582-3591, 2016. https://doi.org/10.1210/jc.2016-2311

IDLER DR, SCHMIDT PJ, RONALD AP: Isolation and identification of 11-ketotestosterone in salmon plasma. Can J Biochem Physiol 38: 1053-1057, 1960. https://doi.org/10.1139/y60-131

O'REILLY MW, KEMPEGOWDA P, JENKINSON C, TAYLOR AE, QUANSON JL, STORBECK KH, ARLT W: 11-Oxygenated C19 steroids are the predominant androgens in polycystic ovary syndrome. J Clin Endocrinol Metab 102: 840-848, 2017. https://doi.org/10.1210/jc.2016-3285

OWEN EJ, HOLOWNIA P, CONWAY GS, JACOBS HS, HONOUR JW: 11ß-hydroxyandrostenedione in plasma, follicular fluid, and granulosa cells of women with normal and polycystic ovaries. Fertil Steril 58: 713-718, 1992. https://doi.org/10.1016/S0015-0282(16)55317-5

PRETORIUS E, AFRICANDER DJ, VLOK M, PERKINS MS, QUANSON JL, STORBECK KH: 11-keto-testosterone and 11-ketodihydrotestosterone in castration resistant prostate cancer: potent androgens which can no longer be ignored. PLoS One 11: e0159867, 2016. https://doi.org/10.1371/journal.pone.0159867

PUTZ Z, HAMPL R, VELEMÍNSKÝ J, KREZE A, ŠULCOVÁ J, STÁRKA L: Radioimmunoassay of $11 \beta$-hydroxyandrostendione in laboratory diagnostics of selected endocrine disorders. J Clin Chem Clin Biochem 25: 723-727, 1987. https://doi.org/10.1515/cclm.1987.25.10.723

REGE J, NAKAMURA Y, SATOH F, MORIMOTO R, KENNEDY MR, LAYMAN LC, HONMA S, SASANO H, RAINEY WE: Liquid chromatography-tandem mass spectrometry analysis of human adrenal vein 19-carbon steroids before and after ACTH stimulation. J Clin Endocrinol Metab 98: 1182-1188, 2013. https://doi.org/10.1210/jc.2012-2912

REGE J, TURCU AF, KASA-VUBU JZ, LERARIO AM, AUCHUS GC, AUCHUS RJ, SMITH JM, WHITE PC, RAINEY WE: 11-keto-testosterone is the dominant circulating bioactive androgen during normal and premature adrenarche. J Clin Endocrinol Metab 103: 4589-4598, 2018. https://doi.org/10.1210/jc.2018-00736

REGE J, GARBER S, CONLEY AJ, ELSEY RM, TURCU AF, AUCHUS RJ, RAINEY WE: Circulating 11-oxygenated androgens across species. J Steroid Biochem Mol Biol 190: 242-249, 2019. https://doi.org/10.1016/j.jsbmb.2019.04.005

SKIBA MA, BELL RJ, ISLAM RM, HANDELSMAN DJ, DESAI R, DAVIS SR: Androgens during the reproductive years: what is normal for women? J Clin Endocrinol Metab 104: 5382-5392, 2019. https://doi.org/10.1210/jc.2019-01357

STORBECK KH, BLOEM LM, AFRICANDER D, SCHLOMS L, SWART P, SWART AC: 11ß-Hydroxydihydrotestosterone and 11-ketodihydrotestosterone, novel C19 steroids with androgenic activity: a putative role in castration resistant prostate cancer? Mol Cell Endocrinol 377: 135-146, 2013. https://doi.org/10.1016/j.mce.2013.07.006

STORBECK KH, SCHIFFER L, BARANOWSKI ES, CHORTIS V, PRETE A, BARNARD L, GILLIGAN LC, TAYLOR AE, IDKOWIAK J, ARLT W, SHACKLETON CHL: Steroid metabolome analysis in disorders of adrenal steroid biosynthesis and metabolism. Endocr Rev 40: 1605-1625, 2019. https://doi.org/10.1210/er.2018-00262

SWART AC, SCHLOMS L, STORBECK KH, BLOEM LM, TOIT TD, QUANSON JL, RAINEY WE, SWART P: $11 \beta$-hydroxyandrostenedione, the product of androstenedione metabolism in the adrenal, is metabolized in LNCaP cells by $5 \alpha$-reductase yielding $11 \beta$-hydroxy-5 $\alpha$-androstanedione. J Steroid Biochem Mol Biol 138: 132-142, 2013. https://doi.org/10.1016/j.jsbmb.2013.04.010 
TURCU AF, NANBA AT, CHOMIC R, UPADHYAY SK, GIORDANO TJ, SHIELDS JJ, MERKE DP, RAINEY WE, ANCHUS RJ: Adrenal-derived 11-oxygenated 19-carbon steroids are the dominant androgens in classic 21-hydroxylase deficiency. Eur J Endocrinol 174: 601-609, 2016. https://doi.org/10.1530/EJE-15-1181

TURCU AF, AUCHUS RJ: Clinical significance of 11-oxygenated androgens. Curr Opin Endocrinol Diabetes Obes 24: 252-259, 2017. https://doi.org/10.1097/MED.0000000000000334

TURCU AF, NANBA AT, AUCHUS RJ: The rise, fall, and resurrection of 11-oxygenated androgens in human physiology and disease. Horm Res Paediatr 89: 284-291, 2018. https://doi.org/10.1159/000486036

YOSHIDA T, MATSUZAKI T, MIYADO M, SAITO K, IWASA T, MATSUBARA Y, OGATA T, IRAHARA M, FUKAMI M: 11-oxygenated C19 steroids as circulating androgens in women with polycystic ovary syndrome. Endocrine J 65: 979-990, 2018. https://doi.org/10.1507/endocrj.EJ18-0212 